\title{
AC 2011-1963: EDUCATING BROAD THINKERS: A QUANTITATIVE ANAL- YSIS OF CURRICULAR AND PEDAGOGICAL TECHNIQUES USED TO PROMOTE INTERDISCIPLINARY SKILLS
}

David B. Knight, Pennsylvania State University, University Park

David Knight is a $\mathrm{PhD}$ candidate in the Higher Education Program at Pennsylvania State University and is a graduate research assistant on two NSF-funded engineering education projects. His research interests include STEM education, interdisciplinary teaching and research, organizational issues in higher education, and leadership and administration in higher education. Email: dbk144@psu.edu 


\section{Educating Broad Thinkers: A Quantitative Analysis of Curricular and Pedagogical Techniques Used to Promote Interdisciplinary Skills}

\section{Introduction}

As problems of modern-day society increase in complexity, addressing issues from multiple perspectives is essential for finding solutions ${ }^{1}$. To address this need, the federal government has called for a shift from discipline-based approaches to interdisciplinary ones to foster more innovative research and results. The Spellings' Commission identified disciplinarity as a major barrier to progress for higher education and asserted that innovation occurs at the intersections of fields $^{2}$. Thus, the National Academy of Engineering ${ }^{3}$, National Academy of Sciences ${ }^{4}$, and National Institute of Health ${ }^{5}$ identified interdisciplinary issues as pressing for society, working under the assumption that interdisciplinary educational approaches more effectively foster innovation than discipline-based educational programs. ${ }^{2,3}$. Such a shift is presumed to promote U.S. global competitiveness, national security, and economic prosperity ${ }^{2,3,6}$.

Integrating interdisciplinarity into the undergraduate curricula better prepares students for the workforce and for civic participation by facilitating the development of problem solving and critical thinking skills ${ }^{7,8,9}$. Thus, ABET's accreditation Criterion 3.d calls for all engineering programs to prepare undergraduate engineers to work in multidisciplinary teams as these will be a feature of the future engineering workplace ${ }^{3,10}$. Employees will be required to apply tools, methods, and knowledge from multiple disciplines concurrently with recognizing the societal constraints and repercussions associated with different solutions ${ }^{3}$. Despite these demands, there are few empirical studies at the college level to support the claim that interdisciplinary study has positive effects on learning ${ }^{11}$ — there is a void in the literature linking students' interdisciplinary learning outcomes to educational practices, especially in engineering education contexts.

An analysis of interdisciplinary courses suggested that the combination of interdisciplinary content and active learning pedagogy seems to promote learning in interdisciplinary courses ${ }^{11}$. This poses a challenge to researchers to understand the unique contributions of content and pedagogy on interdisciplinary learning. This study takes up that challenge, aiming to disentangle the influence of curricular emphases on interdisciplinary course content from active/studentcentered pedagogical techniques to determine how each contribute to the development of students' interdisciplinary skills. The paper aims to identify1) the influences of curricular emphases on interdisciplinary learning, and 2) the role that active/student-centered pedagogical techniques contribute to the interdisciplinary skills of undergraduate engineers.

\section{Defining Interdisciplinarity}

Academic disciplines and fields have traditionally framed the thinking and intellectual activity of their participants ${ }^{12,13,14}$. They create a set of examples and norms used to make generalizations and models that teach members of each group how to view knowledge and approach problem solving in a similar manner ${ }^{15}$. Interdisciplinarity, in contrast, considers the interaction among two or more disciplines in an effort to solve a problem across the traditional boundaries that structurally comprise the university. However, many definitions and interpretations confound the term "interdisciplinarity." 
Scholars often distinguish between "multidisciplinarity" and "interdisciplinarity." They argue that though multidisciplinarity brings two or more disciplines to bear on a problem, there is no attempt to integrate concepts, theories, or methods from different disciplines into a seamless whole. Interdisciplinarity, rather, achieves this synthesis of disciplinary knowledge and methods and thus provides a more holistic understanding of a problem or phenomenon ${ }^{16,17,18,19,20,21}$. In a commonly cited definition, interdisciplinarity is "a process of answering a question, solving a problem, or addressing a topic that is too broad or complex to be dealt with adequately by a single discipline or profession... [by] draw[ing] upon disciplinary perspectives and integrat[ing] their insights through construction of a more comprehensive perspective" (p. 393-394) ${ }^{22}$.

Though scholars commonly debate these definitions, most college and university faculty members are either unaware or unconcerned with such distinctions and tend to use the terms interchangeably ${ }^{23,24,25,26,27}$. One might argue that definitional differences are inconsequential; it is the practice that matters. Variations in the use of the term, however, show that faculty in the same educational programs have differing views of interdisciplinarity and what an education that stresses interdisciplinarity entails $\mathrm{s}^{24,25,27}$. For this reason, instruments used to measure interdisciplinarity must use specific operational definitions that specify interdisciplinary educational activities to gauge how faculty members emphasize interdisciplinarity.

\section{The Interplay of the Curriculum and Pedagogy}

Research suggests that interdisciplinary courses are more engaging than traditional departmentbased courses because they better capture students' intellectual interests ${ }^{11}$. As shown, some claim that integrating interdisciplinary topics into curricula better prepares students for postcollege work settings because the practice facilitates the development of problem solving and critical thinking skills ${ }^{7,8,9}$. Students and instructors may also have more opportunities to connect new knowledge with existing knowledge, as they must use information from their primary disciplines to solve complex problems concurrently with the ideas or tools from other disciplines ${ }^{11}$. Nearly a decade ago, Vess ${ }^{28}$ identified the need to "chart the connections among theory, pedagogy, course enactment, and student perceptions of the learning environment" (p. 96). Moreover, she suggested exploring the connections between the enactment of various models of interdisciplinarity and actual learning as reflected in coursework and later performance, as models of interdisciplinarity range from the mere mentioning of topics from a different field to the complete merging of two disciplines.

Active, problem-based learning pedagogical techniques have been successful in introducing topics from unfamiliar fields to students since problem-based learning demands the consideration of real-world problems. Intuitively, combining interdisciplinary content with active learning appears to promote learning in interdisciplinary courses ${ }^{11}$. In a comparison of active and traditional learning pedagogies in engineering programs, Terenzini et al. ${ }^{29}$ found that students in active learning settings have statistically significant advantages in overall learning outcomes, specifically in design skills, communication skills, and group skills. Similarly, Springer et al. ${ }^{30}$ found that collaborative learning styles yield increases in student persistence for STEM fieldsthis has been especially true for the persistence of women ${ }^{31,32}$. In general, there has been a slow realization among STEM faculty members that instructional methods should be retooled to incorporate interactively-designed courses that begin with questions relevant to everyday life ${ }^{33}$. 
Although both the curricular content and instructional techniques employed in the classroom have been shown to influence interdisciplinary learning, researchers have not yet separated the contributions of each empirically. This paper aims to accomplish this task by determining how curricular emphases and active/student-centered pedagogical techniques separately and jointly contribute to the development of students' interdisciplinary skills in engineering programs.

\section{Conceptual Framework}

Pascarella and Terenzini ${ }^{34,35}$ clearly demonstrate that a student's content acquisition and higherorder thinking skills, among many other outcomes, are enhanced by experiences during their college years. The conceptual model for this study (Figure 1) is a subsection of a larger model by Terenzini and Reason ${ }^{36,37}$, which conceptually combines factors that form the "Undergraduate Experience" in an effort to explain student learning outcomes and persistence and bring overall coherence to research examining the effects of college on student development (Figure 1). The Terenzini and Reason ${ }^{36,37}$ model has undergone several iterations in studies of engineering education to produce a systems view of undergraduate learning that 1) addresses the role of students' characteristics and prior experiences, and 2) considers the influence of organizational conditions (e.g., policies affecting classroom-level practices), program-level faculty culture, and program policies and practices related to teaching and learning.

It hypothesizes that student engagement is shaped by a variety of curricular, classroom, and outof-class experiences and conditions. Since both cognitive skill development and content learning occurs most readily within academic courses ${ }^{35}$, this paper focuses on the curricular and classroom experience components, as shown in Figure 1. Curricular content is a focus in this analysis, specifically, the interdisciplinary topics that programs emphasize throughout the curriculum in their major. Research shows that curricular experiences help develop students' skills ${ }^{38}$, although course content alone does not necessarily yield desired academic skill development for students ${ }^{39,40}$, so instructional practices are also considered. Though traditional lecture-style teaching techniques are still most commonly used in the classroom ${ }^{41,42}$, engaging students through active-learning pedagogies produces greater cognitive skill development than lecture-style teaching ${ }^{35,43}$.

Therefore, this study applies a portion of the Terenzini and Reason mode ${ }^{36,37}$ to the development of interdisciplinary skills and attempt to identify the extent to which curricular and classroom experiences contribute to students' learning outcomes. A related paper ${ }^{44}$ addresses the impact of the curriculum and co-curriculum on interdisciplinary learning outcomes. Understanding the potential influences on students' gains in interdisciplinary skills can help instructors and curriculum planners focus efforts.

Thus, the research questions that guide this study are as follows:

Research Question \#1. Are students' interdisciplinary skills enhanced during college; that is, do students earlier in their major program report less developed interdisciplinary skills than those later in their major programs?

Research Question \#2.To what extent do curricular emphases and/or classroom pedagogies contribute to the development of interdisciplinary skills? 
Figure 1.Conceptual framework for this study.

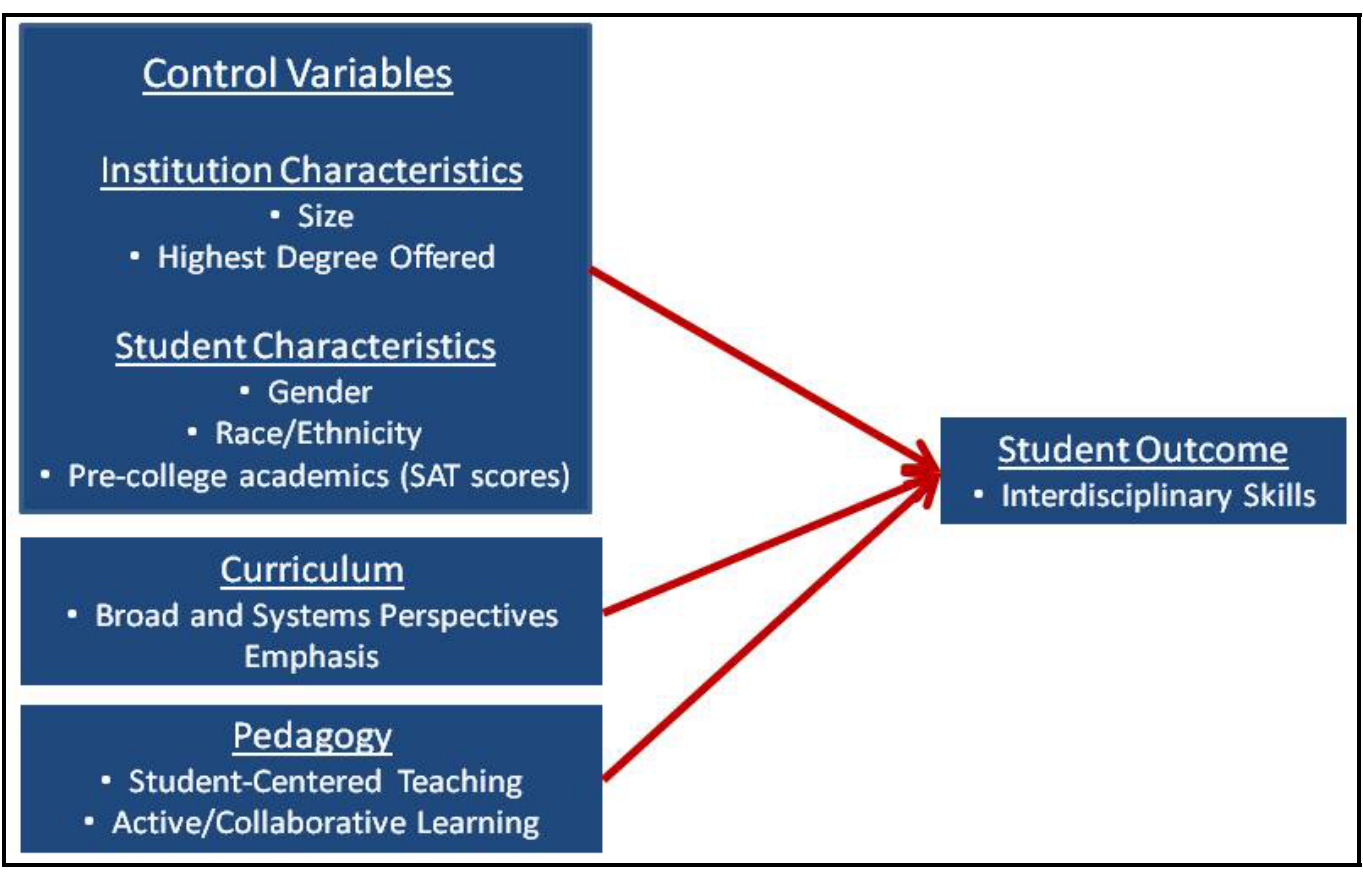

\section{Methods}

The broader study from which this paper is drawn, Prototype to Production: Conditions and Processes for Educating the Engineer of 2020 (P2P), was funded by the National Science Foundation (NSF EEC-00506080). It produced a nationally representative sample of 31 fouryear institutions to generate a greater understanding of education of undergraduate engineers (Table 1). Survey-based instruments were developed following a rigorous, two-year process, including: 1) literature reviews on key topics using the ASEE database, Compendex, and various higher education databases; 2) individual interviews with administrators, faculty, and alumni at Penn State University and City College of New York, the home institutions of the co-principal investigators; and 3) focus-group interviews with students at those same institutions. This study analyzes a survey instrument given to undergraduate engineering students following those information gathering efforts. To ensure that both content validity and items/response options were comprehendible and appropriate, the research team conducted focus group interviews with students from Penn State University, the home institution of the co-principal investigators, to review the instrument prior to sending them to sample institutions. Survey items originated from both other instruments previously used and from focus groups during pilot testing.

\section{Sample and Data Collection}

The sampling frame for this data set was drawn from the American Society for Engineering Education's database using institution and program-level information for the 2007-08 academic year. It is a disproportionate, random, $6 \times 3 \times 2$ stratified sampling that used the following strata: 6 engineering disciplines (biomedical/bioengineering, chemical, civil, electrical, industrial, and mechanical); 3 levels of highest degree offered (bachelor's, master's, and doctorate); and two levels of institutional control (public and private). This design ensured that institutions in the 
final sample are representative of the population with respect to type, mission, and highest degree offered. In addition, programs offering a general engineering degree were added to the final sample. Together, these seven disciplines accounted for $70 \%$ of all baccalaureate engineering degrees awarded in 2007.

The sample was "pre-seeded" with five case study institutions that were participants in a companion qualitative study. Since one of the case study institutions offers only a general engineering degree, three institutions with general engineering programs were also purposely selected for the sample. Penn State's Survey Research Center selected 23 additional institutions at random from the population within the sampling framework, including two historically black colleges and universities and three Hispanic serving institutions.

Surveys were administered to engineering undergraduates to generate a better understanding of current curriculum and instructional techniques, learning environments, administrative and organizational policies/practices, and student educational experiences and outcomes. These data were collected through a web-based questionnaire, following procedures recommended by Dillman, Smith and Christian ${ }^{45}$. Of the 32,737 student surveys sent, 5,249 were returned for a response rate of $16 \%$. Though a higher response rate was certainly desired, response rates around the country have been declining ${ }^{46,47}$, perhaps because of increased use of surveys in general through web-based forms ${ }^{48,49}$. The research team weighted and adjusted responses to be representative of the overall population within institutions, accounting for gender, discipline, and race/ethnicity within an institution. Thus, despite the low response rate, the methods used ensured that the sample was reflective of the overall population surveyed.

In addition, missing data were imputed based on procedures recommended by Dempster, Laird and Rubin ${ }^{50}$ and Graham ${ }^{51}$ using the Expectation-Maximization (EM) algorithm of the Statistical Package for the Social Sciences (SPSS) software (v.19). To reduce data from several survey items into fewer scales, a principal axis analysis (Oblimin with Kaiser Normalization rotation) was completed. Each item was assigned to a factor based on the magnitude of the loading, the effect of keeping or discarding the item on the scale's internal consistency reliability, and according to professional judgment. Factor scales were formed by taking the sum of respondents' scores on the component items on a factor and dividing by the number of items in the scale, as prescribed by Armor ${ }^{52}$.

\section{Variables}

Following this study's conceptual framework, student demographic characteristics and student pre-college academic abilities, as measured by student-reported SAT critical reading and math scores, are incorporated as control variables. In this paper, independent and dependent variables related to the curriculum, pedagogical techniques, and interdisciplinarity skills were used (Table 2). Students were asked to indicate the emphasis of various topics and skills throughout the curriculum, and the broad and systems perspectives scale is related to interdisciplinary content (the term "curriculum" refers to this particular curricular emphasis throughout the paper). Scales pertaining to pedagogical techniques include active/collaborative learning and student-centered teaching (similarly, "pedagogy” refers to these particular instructional strategies). Though individual items were not related to activities specifically related to engaging in material across 
disciplines, some literature has suggested that active pedagogies in particular in which students collaborate in groups or teams may lead to skill development in this area ${ }^{28}$. Finally, students were asked to rate their proficiencies in various skills and topics. The interdisciplinary skills outcome scale serves as the dependent variable for this paper.

\section{Analytical Procedures}

Several descriptive statistics identify the extent to which interdisciplinary education is emphasized in the curriculum as well as the extent to which various pedagogical techniques are implemented across the engineering disciplines. Analyses of covariance (ANCOVA) were run to compare multiple groups (across disciplines) with the appropriate post-hoc test implemented to identify specific differences.

\section{Table 1: P2P Institutional Sample}

\begin{tabular}{|c|c|}
\hline Research Institutions: & Master's/Special Institutions: \\
\hline Arizona State University (Main \& Polytechnic) $)^{1}$ & California Polytechnic State University ${ }^{3}$ \\
\hline Brigham Young University & California State University, Long Beach \\
\hline Case Western Reserve University & Manhattan College \\
\hline Colorado School of Mines & Mercer University \\
\hline Dartmouth College & Rose-Hulman Institute of Technology \\
\hline Johns Hopkins University & University of South Alabama \\
\hline \multicolumn{2}{|l|}{ Massachusetts Institute of Technology ${ }^{1}$} \\
\hline \multicolumn{2}{|l|}{ Morgan State University ${ }^{2}$} \\
\hline New Jersey Institute of Technology & Baccalaureate Institutions: \\
\hline North Carolina A\&T² & Harvey Mudd College $^{1}$ \\
\hline Purdue University & Lafayette College \\
\hline Stony Brook University & Milwaukee School of Engineering \\
\hline University of Illinois at Urbana-Champaign & Ohio Northern University \\
\hline University of Michigan $^{1}$ & Penn State Erie, The Behrend College \\
\hline University of New Mexico ${ }^{3}$ & West Virginia University Institute of Technology \\
\hline \multicolumn{2}{|l|}{ University of Texas, El Paso ${ }^{3}$} \\
\hline \multicolumn{2}{|l|}{ University of Toledo } \\
\hline Virginia Polytechnic Institute and State University ${ }^{1}$ & \\
\hline
\end{tabular}

Research Question \#1. An ANCOVA was used to determine the development of students' selfreported interdisciplinary skills across academic years (sophomore, junior, and senior). This analysis controls for pre-college academic preparation as measured by SAT scores, nonacademic characteristics (gender and race/ethnicity), and engineering discipline. Using student self-reporting of learning outcomes is a common practice in higher education-research shows high correlations between student self-reporting and abilities as measured by grades and test scores $^{53}$. When objective tests of skills, such as interdisciplinarity, are not available, student selfreports are a useful alternative. Thus, in concert with social science research norms ${ }^{54}$, statistically significant differences in interdisciplinary skill responses as aggregated by academic year should identify legitimate differences across groups. 
Table 2. Curriculum emphasis, pedagogy, and outcome scales for student survey. The Cronbach's alpha indicates the internal consistency reliability. Values can range from .00 to 1.00. Psychometricians consider scales greater than .70 to be acceptable.

\section{Curriculum: Broad and Systems Perspectives Emphasis (alpha=.84)}

Overall, how much have the courses you've taken in your engineering program emphasized each of the following :

Understanding how an engineering solution can be shaped by environment, cultural, economics, and other considerations.

Understanding how non-engineering fields can help solve engineering problems.

Systems thinking.

Applying knowledge from other fields to solve an engineering problem.

Pedagogy: Student-Centered Teaching (alpha=.81)

In your engineering courses, how often have your instructors: ${ }^{2}$

Set clear expectations for performance.

Conveyed the same material in multiple ways (in writing, diagrams, orally, etc.).

Explained new concepts by linking them to what students already know.

Used examples, cases, or metaphors to explain concepts.

Answered questions or gone over material until students "got it."

Pedagogy: Active/Collaborative Learning (alpha=.77)

In your engineering courses, how often have your instructors: ${ }^{2}$

Provided guidance or training in how to work effectively in groups.

Provided hands-on activities and/or assignments.

Used in-class, small group learning.

Assigned group projects.

Outcome: Interdisciplinary Skills (alpha $=.80$ )

Do you agree or disagree? ${ }^{3}$

I value reading about topics outside of engineering.

I enjoy thinking about how different fields approach the same problem in different ways.

Not all engineering problems have purely technical solutions.

In solving engineering problems I often seek information from experts in other academic fields.

Given knowledge and ideas from different fields, I can figure out what is appropriate for solving a problem.

I see connections between ideas in engineering and ideas in the humanities and social sciences.

I can take ideas from outside engineering and synthesize them in ways to better understand a problem.

I can use what I have learned in one field in another setting or to solve a new problem.

${ }^{1}$ 1: Little/no emphasis; 2: Slight; 3: Moderate; 4:Strong; 5: Very strong

${ }^{2}$ 1: Never; 2: Rarely; 3: Sometimes; 4: Often; 5: Very often

${ }^{3}$ 1: Strongly disagree; 2: Disagree; 3: Neither agree nor disagree; 4: Agree; 5: Strongly agree

Research Question \#2. Multiple linear regression was used to determine the extent to which the curriculum and pedagogical techniques explain the interdisciplinary skills learning outcome among seniors. Control variables are identical to the previous analysis, with the exception of academic discipline. Separate regression analyses were run for each discipline to show differences in the relative impact of curriculum and pedagogy across engineering programs. Comparisons across beta values identify the relative importance of each independent and control variable to the interdisciplinary skill dependent variable. 
This study has two major limitations. For the first research question, the cross-sectional nature of the survey potentially confounds findings of differences across academic years since the progression through a program is represented by different groups of students. Longitudinal data were not available, but this is an attempt to identify the development of interdisciplinary skills throughout a program. Secondly, program emphases are those identified by students who may not recognize the broad rationale for certain pieces of the curriculum. However, a companion paper that incorporates curricular emphases as identified by faculty or program chairs showed consistencies with student-reported emphases ${ }^{44}$.

\section{Results and Discussion}

Differences were found for means across engineering subdisciplines for the broad and systems perspectives curriculum emphasis, pedagogy, and the interdisciplinary skills outcome scales (Figure 2), though the overall variation among the disciplines for each scale was fairly small. This analysis shows results for seniors in their fourth or fifth year because students are presumably characterizing their entire curriculum, teaching, and learning experience. Sophomores or juniors, who have not progressed as far into their academic programs, are reporting on these experiences and thus do not fully comprehend the scope of the program and the extent of its emphasis on interdisciplinarity.

As the figure shows, industrial engineers responded significantly higher than other students on the curriculum and pedagogy scales (according to an ANCOVA, controlling for gender, race, and precollege academic preparation). However, the average responses for all majors on nearly all scales tended to be on the more positive side of the scale (3 or higher). The high reports of these particular curricular and classroom experiences correspond with reports of strong interdisciplinary skills for these students, consistent according to the conceptual framework that classroom experiences may influence student learning outcomes. Mechanical engineering seniors reported only a slight to moderate emphasis on broad and systems perspectives and the lowest of all engineering majors on any scale. This corroborates work by Pierrakos, Borrego, and $\mathrm{Lo}^{55}$ that used mechanical engineering senior design teams as a "disciplinary" comparison for an interdisciplinary bioengineering senior design team. Similar to that study's findings, student outcomes for this sample are higher for “interdisciplinary” biomedical/bioengineering students compared to "disciplinary” mechanical engineers. These consistent patterns across investigations enhance confidence in the current findings.

Interestingly, despite reporting the highest interdisciplinary skills, general engineering students tended to report lower than industrial engineers on the student experience scales. It is assumed for this study that general engineering is an inherently discipline boundary-spanning program. This assumption stems from a companion NSF-funded study which conducted in-depth case studies of six engineering institutions, including Harvey Mudd College and Arizona State University-Polytechnic campus with general engineering programs ( 2 of the 5 general engineering programs in this study's sample). These institutions take a multidisciplinary approach to engineering, pay particular attention to systems and design thinking and enroll students who do not declare a major in a traditional engineering subdiscipline. Two rationales may explain the lower curricular emphasis and pedagogical techniques reported by general 
engineers, as shown in Figure 2. First, general engineering in particular may be perceived as building disciplinary strength across engineering fields rather than focusing on the connections among these fields. Alternatively, because nearly every aspect of these programs is designed to incorporate broad and systems perspectives, respondents may simply not recognize this intention on a daily basis. Considering the outcomes, however, it is not surprising that these students on average reported the highest level of interdisciplinary skills.

The means for student-centered teaching as reported by biomedical/bioengineers along with active/collaborative learning as reported by general engineers were among the lowest rankings of all the disciplines. This provides a preliminary answer for the second research question in determining how pedagogical techniques influence interdisciplinary learning (perhaps very little), but a subsequent in-depth analysis directly addresses this question. Though the items comprising the pedagogy scales were not directly related to interdisciplinarity, it is interesting that students from these "interdisciplinary" programs seem to report the least effective teaching practices. Electrical engineers also reported that active/collaborative learning experiences only occur "sometimes." Thus, regardless of whether such practices may lead to the development of interdisciplinary skills, an opportunity may exist within this discipline to incorporate more innovative pedagogies that have been shown to be associated with higher cognitive skill development in general $^{35,43}$.

Students' interdisciplinary skills significantly increased from the sophomore to the junior year $(\mathrm{p}<0.01)$, controlling for both discipline and non-academic/academic student background characteristics (Figure 3). Seniors' interdisciplinary skills are also significantly greater than those reported by sophomores $(\mathrm{p}<0.001)$, and there is no significant difference reported between juniors and seniors. This answers the first research question-student-reported interdisciplinary skills are higher for students further along in their major programs relative to students earlier in their program. As such, there is some evidence that interdisciplinary skills are enhanced during college- while the results in Figure 2 suggest that curricular differences influence interdisciplinary skills, the role of pedagogy, outside of basic effective teaching practices, is still unclear because of the limitations of the pedagogy scales used in this analysis.

The higher skill level reported by upperclassmen relative to their underclassmen colleagues is consistent with prior work on engineering education. Longitudinal studies of undergraduate engineering students show little cognitive development during the first two years of college; the first two years of the engineering curriculum are typically comprised of rote learning and application of formulae, foundational science and math courses that tend to not promote reflective thinking ${ }^{56,57}$. In higher level courses during the third and fourth years, however, a different educational environment may play a role in cognitive development. Recent work by Arum and Roksa ${ }^{58}$ also suggests limited development of critical thinking skills and complex reasoning during a student's first two years of college. Since interdisciplinary skills require higher order thinking skills such as synthesis and evaluation, the increase among students from their second to third year demonstrated in this analysis is consistent with expectations. Therefore, in accordance with the conceptual framework, results showing the development of interdisciplinary skills over the course of a program suggest that some components of the college experience likely contribute to these gains for students. 
Figure 2. Mean scale scores for seniors for interdisciplinary-related curricular and pedagogical experiences and learning outcomes for each engineering subdiscipline.

\begin{tabular}{|c|c|c|c|c|c|c|c|c|}
\hline \multicolumn{9}{|c|}{ CURRICULUM: BROAD AND SYSTEMS PERSPECTIVES 1} \\
\hline 2.8 & 2.9 & 3.0 & 3.1 & 3.2 & 3.3 & 3.4 & 3.5 & 3.6 \\
\hline & 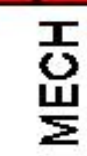 & $\sum_{\bar{S}}$ & $\frac{\mathrm{o}}{\mathrm{m}}$ & & & & & $\begin{array}{l}\stackrel{\infty}{马} \\
\underline{2}\end{array}$ \\
\hline
\end{tabular}

\begin{tabular}{|c|c|c|c|c|c|c|c|c|}
\hline PEDAGO & STUL & Cl & RE & EAC & & & & \\
\hline 3.70 & 3.75 & 3.80 & 3.85 & 3.90 & 3.95 & 4.00 & 4.05 & 4.10 \\
\hline & 겅응 & 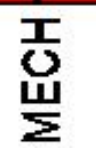 &  & $\frac{1}{0}$ & & $\begin{array}{l}\stackrel{0}{3} \\
\text { ㅇ }\end{array}$ & & \\
\hline
\end{tabular}

PEDAGOGY: ACTIVE/COLLABORATIVE LEARNING?

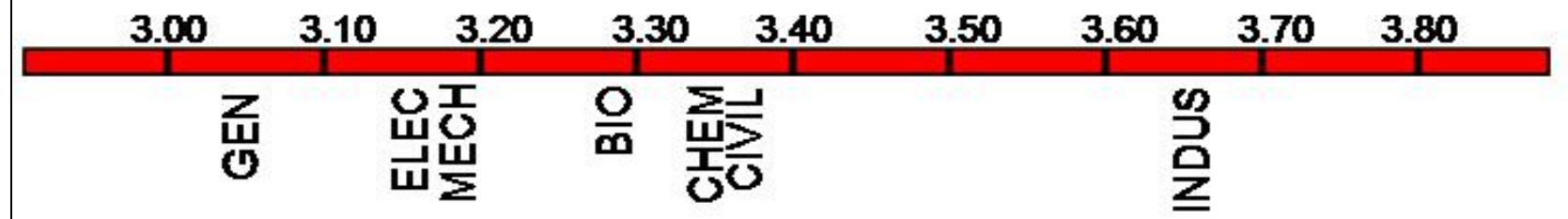

OUTCOME: INTERDISCIPLINARY SKILLS ${ }^{3}$

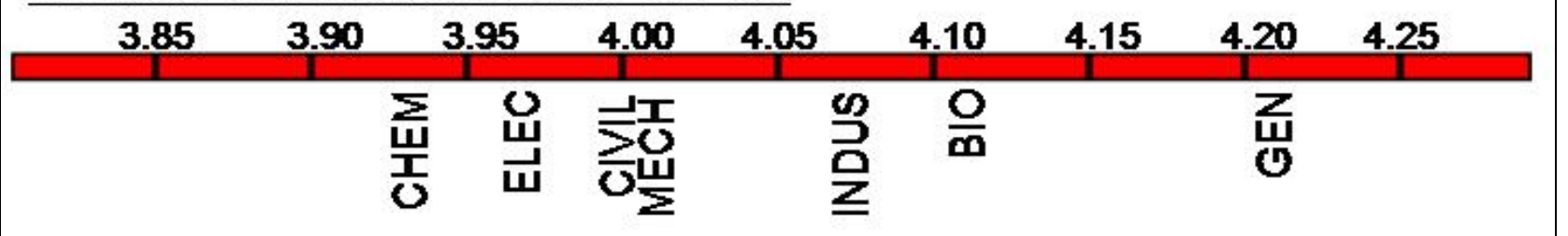

${ }^{1}$ 1: Little/no emphasis; 2: Slight; 3: Moderate; 4:Strong; 5: Very strong

${ }^{2} 1$ : Never; 2: Rarely; 3: Sometimes; 4: Often; 5: Very often

${ }^{3} 1$ : Strongly disagree; 2: Disagree; 3: Neither agree nor disagree; 4:Agree; 5: Strongly agree

Figure 3. Mean interdisciplinary skill scores aggregated by academic year. According to an ANCOVA (covariates: SAT, gender, race/ethnicity, and discipline), seniors $(\mathrm{p}<0.001)$ and juniors $(\mathrm{p}<0.01)$ report significantly higher interdisciplinary skills than sophomores.

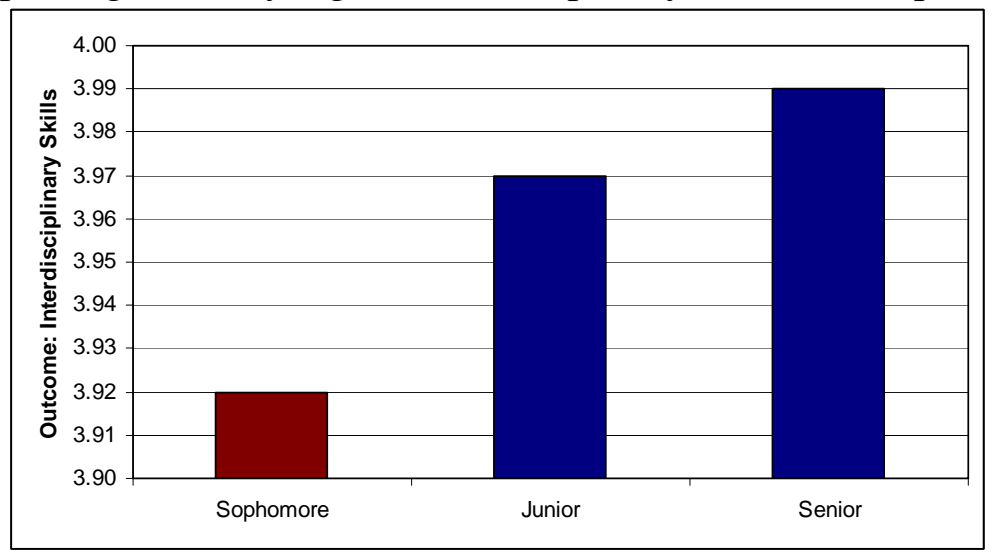


Finally, a multiple regression analysis was used to determine the impact of both curriculum and pedagogy on interdisciplinary skills. Results from an overall regression and for individual disciplines are shown in Table 3. Several observations can be made from this table:

1. Both the curriculum and pedagogical techniques are predictors of seniors' interdisciplinary skills. Because the $\mathrm{R}^{2}$ value of each increases with the inclusion of the other, both partially explain the variance in the learning outcome. This finding provides empirical support for the conceptual framework as higher reports of student experiences variables are associated with higher reports of student outcomes.

2. Considering all engineering students, emphasizing broad and systems perspectives is over three times as strong of a predictor as student-centered teaching. Active/collaborative learning does not influence interdisciplinary skills according to this regression.

3. Analyses should examine each engineering discipline separately rather than controlling for discipline. Differences across columns in Table 3 show that the control variables, curriculum, and pedagogical techniques differ in how and to what extent they predict interdisciplinary skills depending on the discipline of focus.

4. The curriculum has a greater influence than pedagogy on interdisciplinary skills for seniors in all majors except industrial engineers. Increasing content that requires students to think beyond the scope of their disciplines could have a positive influence on interdisciplinary skill development in these programs. It is important to recognize the intentionality of the curricular content as shown by this study of the development of interdisciplinary skills. Simply having students work in groups without a clearly defined objective of searching for connections across content area boundaries, for example, may not produce the desired interdisciplinary skill development.

5. For biomedical/bioengineers and civil engineers, active/collaborative learning is positively associated with interdisciplinary skills - successful techniques from these disciplines might be adapted for other majors to promote further interdisciplinary skill development.

6. Pedagogies have a greater influence than the curriculum on interdisciplinary skills for industrial engineers, with student-centered teaching showing the strongest relationship with interdisciplinary skill development. However, as shown in Figure 2, industrial engineers report the highest averages for the curriculum and pedagogy scales. Thus, it is intuitive that both the curriculum and pedagogy have nearly the same magnitude of influence on interdisciplinary skills for these students (as supported by Table 3).

7. These curriculum, pedagogies, and control variables have varying abilities across engineering disciplines to predict interdisciplinary skills. At most, they predict $41 \%$ of the variance for industrial engineers; at least, they predict $16 \%$ of the variance for electrical engineers.

8. For all engineering subdisciplines except industrial and general engineering (and engineering seniors in aggregate), a student's SAT critical reading score is a good predictor of their senior-year, self-reported interdisciplinary skills. Since the critical reading test is partly 
designed to assess analogical reasoning ${ }^{59}$, it stands to reason that students exhibiting this ability before matriculation would excel at further developing interdisciplinary skills, an expertise that requires students to be able to make connections across fields. What this analysis shows is that critical reading and analogical reasoning may be the fundamentals required for interdisciplinary thinking, much like mathematics has been shown to be the fundamental skills required for problem solving and design.

Table 5. Betas for multiple regression analyses with the student-reported interdisciplinary skills outcome as the dependent variable. Each column represents a separate regression, and betas are included for the statistically significant variables. Two sets of $\mathrm{R}^{2}$ values are presented to show the differential influence of entering the curriculum variable prior to the pedagogy variables and vice versa. Shadings indicate whether entering the curriculum variable or pedagogy variables explained a greater amount of variance.

\begin{tabular}{|c|c|c|c|c|c|c|c|c|c|}
\hline & & All & Bio & Chem & Civ & Elec & Gen $^{1}$ & Ind & Mech \\
\hline \multirow{15}{*}{$\begin{array}{c}\text { Control } \\
\text { Variables }\end{array}$} & Gender (reference=female) & & & & & & & & \\
\hline & Race $($ reference $=$ White $)$ & & & & & & & & \\
\hline & African American & $-.06^{* *}$ & & & & & & & \\
\hline & Asian American & & & & & & & & \\
\hline & Hispanic/Latino/a American & & & & & & & & \\
\hline & Other & & $-.15^{*}$ & & & & & & \\
\hline & $\begin{array}{l}\text { Institution Size } \\
\text { (reference=large) }\end{array}$ & & & & & & & & \\
\hline & Small & $-.06^{* *}$ & & & & & & & $-.11^{* *}$ \\
\hline & Medium & & & & & & & & $-.08 *$ \\
\hline & $\begin{array}{r}\text { Highest Degree Offered } \\
\text { (reference }=\text { doctorate) }\end{array}$ & & & & & & & & \\
\hline & Bachelors & & & & & & & $.24 *$ & \\
\hline & Masters & & & & & & & & \\
\hline & Pre-College Academics & & & & & & & & \\
\hline & SAT Critical Reading Score & $.22 * * *$ & $.24^{*}$ & $.18^{*}$ & $.37 * * *$ & $.23 * *$ & & & $.30 * * *$ \\
\hline & SAT Math Score & & & & $-.18 * *$ & & & & $-.14^{* *}$ \\
\hline Curriculum & Broad and Systems Perspectives & $.31 * * *$ & $.27 * * *$ & $.34 * * *$ & $.27 * * *$ & $.38 * * *$ & $.32 *$ & $.33 * *$ & $.32 * * *$ \\
\hline \multirow[t]{2}{*}{ Pedagogy } & Student-Centered Teaching & $.09 * * *$ & & & & & & $.38 * * *$ & \\
\hline & Active/Collaborative Learning & & $.30 * *$ & & $.14^{*}$ & & & & \\
\hline \multirow{5}{*}{$\mathbf{R}^{2}$} & Controls & .039 & .080 & .046 & .047 & .042 & .083 & .175 & .062 \\
\hline & Controls + Curriculum & .153 & .200 & .181 & .148 & .151 & .174 & .326 & .179 \\
\hline & $\begin{array}{l}\text { Controls + Curriculum + } \\
\text { Pedagogy }\end{array}$ & .159 & .241 & .190 & .160 & .155 & .199 & .405 & .182 \\
\hline & Controls + Pedagogy & .090 & .194 & .109 & .107 & .060 & .149 & .344 & .107 \\
\hline & $\begin{array}{l}\text { Controls + Pedagogy + } \\
\text { Curriculum }\end{array}$ & .159 & .241 & .190 & .160 & .155 & .199 & .405 & .182 \\
\hline
\end{tabular}




\section{Conclusions and Implications}

Previous work in higher education, such as research implementing the National Survey of Student Engagement ${ }^{60}$, has thoroughly examined various aspects of the college experience. This work takes a step beyond prior research by connecting components of the college experience to a specific learning outcome. It first establishes that students who are further along in their program report higher interdisciplinary skills than students earlier in the program. This suggests that what happens during college may have an influence on the development on this skill. Results also provide evidence that a student's SAT critical reading score positively predicts interdisciplinary skills for certain disciplines and for engineering as a whole. If a program is seeking students with a higher affinity for understanding interdisciplinary topics, the findings of this study suggest that admissions committees could place a greater emphasis on SAT critical reading scores. Students who enter a program with lower SAT critical reading scores might need more targeted instruction to develop this skill. Much like mathematics skills are the foundation for problem solving and design, this study suggests that critical thinking and analogical reasoning may be the building blocks for interdisciplinary skills. Students may first have to have this set of abilities in place before they can effectively work across disciplines.

In addition, these findings begin to untangle the influence of curricular emphases and classroom experiences on the development of students' interdisciplinary skills. For all engineering students, explicitly explanations of connections and linkages among disciplinary concepts and theories during classes contributes to the development of interdisciplinary skill; simply having students work in groups, for example, does not contribute as much to skill enhancement. Analyses treating each discipline separately, however, suggest that some fields have more effective strategies than others fields. These findings are a first step toward advising curriculum and program planners on how to best balance resources and energy between the promotion of classroom content and the use of various pedagogical techniques aimed at the development of interdisciplinary skills. If active/collaborative learning positively influences interdisciplinary skills in a discipline, for example, programs from within that discipline that aim to expand students' abilities to think across disciplinary boundaries can incorporate such pedagogies in the classroom. More research is needed to determine the exact nature of the differences in their approaches, however.

Limitations in the measures of pedagogy used in the research suggest the need for additional study. Specifically, the scales used asked students to report on the frequency with which they experienced a variety of active learning pedagogies in their engineering programs. These measures do not focus specifically on interdisciplinary learning experiences. For example, these scales do not differentiate between students participating in multi-disciplinary engineering teams in first-year or subsequent design courses and more interdisciplinary activities in which they work collaboratively with students from fields outside engineering. Further research should explore the ways in which more specific pedagogies interact in interdisciplinary courses and programs. However, this work does show that innovative pedagogies in general are not as effective as curricular content in promoting interdisciplinary skill development and is a first step toward untangling the influences of each classroom experience. 
To date, the literature focusing on the development of students' interdisciplinary skills has focused on single program case studies. This study contributes to ongoing research by identifying influences on the development of interdisciplinary skills across multiple programs and institutions. Because interdisciplinary skills are sought by the engineering workforce, the federal government, and members of industry, these results will be of interest to faculty and administrators in engineering programs who seek to produce innovative, broad-thinking students. As graduates are asked to solve problems that transcend the boundaries of social, economic, political, environmental, and other realms, research such as this is a first step in furthering knowledge of how to best prepare students for the world in which they will live and work.

\section{References}

${ }^{1}$ Klein, J. T. (2010).Creating Interdisciplinary Campus Cultures: A Model for Strength and Sustainability. San Francisco: Jossey-Bass.

${ }^{2}$ US Department of Education (2006). A test of leadership: Charting the future of American higher education. Report of the commission appointed by Secretary of Education Margaret Spellings.

${ }^{3}$ National Academy of Engineering (2004). The engineer of 2020: Visions of engineering in the new century. Washington, D.C.: National Academies Press.

${ }^{4}$ National Academy of Sciences (2004). Facilitating interdisciplinary research. Washington, D.C.: National Academies Press.

${ }^{5}$ National Institutes of Health (2006).Summary of the President's FY 2006 budget. Washington, D.C.: National Institutes of Health.

${ }^{6}$ National Science Board. (2010). Ch. 2: Higher Education in Science and Engineering. In Science and Engineering Indicators: 2010.National Science Foundation, 2.1-2.48.

${ }^{7}$ Hursh, B., P. Haas, \& Moore, M. (1983). An interdisciplinary model to implement general education. Journal of Higher Education, 54, 42-49.

${ }^{8}$ Newell, W.H. (1990). Interdisciplinary curriculum development. Issues in Integrative Studies, 8, 69-86.

${ }^{9}$ Newell, W.H., \& Green, W.J. (1982). Defining and teaching interdisciplinary studies. Improving College and University Teaching, 30, 23-30.

${ }^{10}$ National Academy of Engineering (2005).Educating the engineer of 2020: Adapting engineering education for the new century. Washington, D.C.: National Academies Press.

${ }^{11}$ Lattuca, L.R., L.J. Voigt \& Fath, K.Q. (2004). Does interdisciplinarity promote learning? Theoretical support and researchable questions. The Review of Higher Education, 28, 23-48.

${ }^{12}$ Whitley, R. (1976).Umbrella and polytheistic scientific discipline and their elites. Social Studies of Science, 4, 1736.

${ }^{13}$ Becher, T. (1989).Academic tribes and territories: Intellectual enquiry and the cultures of disciplines. Bristol, PA: The Society for Research into Higher Education and Open University Press. 
${ }^{14}$ Lattuca, L.R. (2002). Learning interdisciplinarity. The Journal of Higher Education, 73, 711-739.

${ }^{15}$ Kuhn, T.S. (1970).The structure of scientific revolutions $\left(2^{\text {nd }}\right.$ ed., enlarged). Chicago: Chicago University Press.

${ }^{16}$ Collin, A. (2009). Multidisciplinary, interdisciplinary, and transdisciplinary collaboration: Implications for vocational psychology. International Journal for Educational and Vocational Guidance, 9(2), 101-110.

${ }^{17}$ Klein, J. T. (1996).Crossing Boundaries: Knowledge, Disciplinarities, and Interdisciplinarities. Charlottesville: University Press of Virginia.

${ }^{18}$ Kockelmans, J. (1979). Interdisciplinarity and higher education. University Park: The Pennsylvania State University Press.

${ }^{19}$ Miller, R. C. (1982).Varieties of interdisciplinary approaches in the social sciences. Issues in Integrative Studies, $1,1-37$.

${ }^{20}$ O'Donnell, A. M., \& Derry, S.J. (2005). Cognitive processes in interdisciplinary groups: problems and possibilities. In Interdisciplinary collaboration: An emerging cognitive science. S. J. Derry, C. D. Schunn and M. A. Gernsbacher (eds.) (pp. 51-82). Mahwah: Lawrence Erlbaum.

${ }^{21}$ Richards, D. G. (1996).The meaning and relevance of 'synthesis” in interdisciplinary studies. The Journal of Education, 45 (2), 114-28.

${ }^{22}$ Klein, J.T, \& Newell, W.H. (1997). Advancing interdisciplinary studies. In Jerry G. Gaff, James L. Ratcliff and Associates (Eds.). (1997). Handbook of the undergraduate curriculum: A comprehensive guide to purposes, structures, practices, and change (pp. 393-415). San Francisco: Jossey-Bass.

${ }^{23}$ Aram, J. D. (2004). Concepts of interdisciplinarity: Configurations of knowledge and action. Human Relations, 57(4): 379-412.

${ }^{24}$ Carp, R. M. (2001). Integrative praxes: Learning from multiple knowledge formations. Issues in Integrative Studies, 19, 71-121.

${ }^{25}$ Holley, K. A. (2009). Challenge of an interdisciplinary curriculum: a cultural analysis of a doctoral-degree program in neuroscience. Higher Education, 58: 241-255.

${ }^{26}$ Lattuca, L. R. (2001).Creating Interdisciplinarity: Interdisciplinary Research and Teaching among College and University Faculty. Nashville, TN: Vanderbilt University Press.

${ }^{27}$ Lattuca, L.R., \& Knight, D.B. (2010, June). In the eye of the beholder: Defining and studying interdisciplinarity in engineering education. Proceedings of the $117^{\text {th }}$ Annual Conference of the American Society of Engineering Education, Louisville, KY.

${ }^{28}$ Vess, D. (2001).Navigating the interdisciplinary archipelago: The scholarship of interdisciplinary teaching and learning. In M.T. Huber \& S.P. Morreale (Eds.), Disciplinary styles in the scholarship of teaching and learning: Exploring common ground (pp. 87-106). Washington, DC: AAHE/Carnegie Foundation for the Advancement of Teaching.

${ }^{29}$ Terenzini, P.T., A.F. Cabrera, C.L. Colbeck, J.M. Parente, and S.A. Bjorklund. (2001). Collaborative learning vs. lecture/discussion: students' reported learning gains. Journal of Engineering Education 90(1), 123-130.

${ }^{30}$ Springer, L, M.E. Stanne, and S.S. Donovan. (1999). Effects of small-group learning on undergraduates in science, mathematics, engineering, and technology: a meta-analysis. Review of Educational Research 69(1): 21-51.

${ }^{31}$ Dickie, L.O., H. Dedic, S. Rosenfield, E. Rosenfield, and R.A. Simon. (2006). Success and persistence in science: the influence of classroom climate. Arxiv preprint physics/0610243. 
${ }^{32}$ Knight, D.B., Mappen, E.F., \& Knight, S.L.(2011). A review of the literature on increasing the representation of women undergraduates in STEM disciplines through civic engagement pedagogies. Science Education and Civic Engagement, 3(1), 36-47.

${ }^{33}$ Seymour, E. (2001). Tracking the processes of change in US undergraduate education in science, mathematics, engineering, and technology. Science Education 86, 79-105.

${ }^{34}$ Pascarella, E.T. \& P.T. Terenzini (1991). How college affects students: Findings and insights from twenty years of research. San Francisco: Jossey-Bass.

${ }^{35}$ Pascarella, E.T., \& Terenzini, P.T. (2005). How college affects students. San Francisco, CA: Jossey-Bass.

${ }^{36}$ Terenzini, P. T., \& Reason, R. D. (2005, November). Parsing the first-year of college: A conceptual framework for studying college impacts. Paper presented at the Annual Conference of the Association for the Study of Higher Education. Philadelphia, PA.

${ }^{37}$ Terenzini, P. T., \& Reason, R. D. (2010, June). Toward a more comprehensive understanding of college effects on student learning. Paper presented at the Annual Conference of the Consortium of Higher Education Researchers (CHER), Oslo, Norway

${ }^{38}$ Miller, R.L., Ely, J.F., Baldwin, R.M. \& B.M. Olds (1998). Higher-order thinking in the unit operations laboratory. Chemical Engineering Education, 32(2), 146-151.

${ }^{39}$ Case, J.M., \& Fraser, D.M. (1999). Activities to enhance the understanding of the mole and its use in chemical engineering. Chemical Engineering Education, 33(4), 332-335.

${ }^{40}$ Trowridge, D., \& McDermott, L.C. (1981). Investigation of student understanding of the concept of acceleration in one dimension. American Journal of Physics, 49(3), 242-252.

${ }^{41}$ Lindholm, J.A., K. Szelényi, S. Hurtado \& W.S. Korn (2005). The American college teacher: National norms for the 2004-2005 HERI faculty survey. Los Angeles: Higher Education Research Institute, UCLA.

${ }^{42}$ Schuster, J.H. \& M.J. Finkelstein (2006). The American faculty: The restructuring of academic work and careers. Baltimore, MD: The Johns Hopkins University Press.

${ }^{43}$ Lattuca, L. R., \& Stark, J.S. (2009).Shaping the College Curriculum: Academic Plans in Context. San Francisco: Jossey-Bass.

${ }^{44}$ Lattuca, L.R., Trautvetter, L., Codd, S., \& Knight, D.B. (2011). Working as a team: Enhancing interdisciplinarity for the Engineer of 2020. Paper forthcoming at the American Association of Engineering Educators, Vancouver, Canada.

${ }^{45}$ Dillman, D. A., Smyth, J. D., \& Christian, L. M. (2009). Internet, mail, and mixed-mode surveys: The tailored design method (3rd ed.). Hoboken, NJ: Wiley.

${ }^{46}$ Baruch, Y. (1999). Response rate in academic studies-A comparative analysis. Human Relations, 52, 421-438.

${ }^{47}$ Porter, S.R., \& Umbach, P.D. (2001, June). What works best? Collecting alumni data with multiple technologies. Paper presented at the annual meeting of the Association for Institutional Research, Long Beach, CA.

${ }^{48}$ Porter, S.R., \& Umbach, P.D. (2006). Student survey response rates across institutions: Why do they vary? Research in Higher Education, 47(2), 229-247.

${ }^{49}$ Van Horn, P.S., Green, K.E., \& Martinussen, M. (2009). Survey response rates and survey administration in counseling and clinical psychology: A meta-analysis. Educational and psychological measurement, 69, 389-403. 
${ }^{50}$ Dempster, A.P., Laird, N.M., \& Rubin, D.B. (1977).Maximum likelihood from incomplete data via the EM algorithm. Journal of the Royal Statistical Society, Series B, 39, 1-38.

${ }^{51}$ Graham, J.W. (2009). Missing data: Making it work in the real world. Annual Review of Psychology, 60, 549-576.

${ }^{52}$ Armor, D. J. (1974). Theta reliability and factor scaling. In H. Costner (Ed.). Sociological methodology: 19731974. San Francisco: Jossey-Bass, pp. 17-50.

${ }^{53}$ Volkwein, J.F., Lattuca, L.R., Harper, B.J. \& R.J. Domingo (2007). Measuring the impact of professional accreditation on student experiences and learning outcomes. Research in Higher Education, 48(2), 251282.

${ }^{54}$ Kuh, G.D. (2005). Imagine asking the client: Using student and alumni surveys for accountability in higher education. In: Burke, J.C. and Associates (eds.), Achieving accountability in higher education: Balancing public, academic, and market demands. Jossey-Bass, San Francisco, pp. 148-172.

${ }^{55}$ Pierrakos, O., Borrego, M., and Lo, J. (2007). Assessment of student's learning outcomes during design experiences: Empirical evidence to support interdisciplinary teams. Proceedings of the $4^{\text {th }}$ WSEAS/IASME International conference on engineering education, Agios, Crete Islan, Greece (July 24-26).

${ }^{56}$ Marra, R.M., Palmer, B., \& Litzinger, T.A. (2000). The effects of a first-year engineering design course on student intellectual development as measured by the Perry class scheme. Journal of Engineering Education, 89(1), 39-45.

${ }^{57}$ Wise, J.C., Lee, S., Litzinger, T.A., Marra, R.M. \& B. Palmer (2001, June).Measuring cognitive change in engineering undergraduates: A longitudinal study. Paper presented at the American Society for Engineering Education Conference, Albuquerque, NM.

${ }^{58}$ Arum, R., \&Roksa, J. (2010).Academically adrift: Limited learning on college campuses. Chicago, IL: University of Chicago Press.

${ }^{59}$ Davenport, T.R. (2007).Mastering the SAT critical reasoning test. Hoboken, NJ: Wiley Publishing, Inc.

${ }^{60}$ Kuh, G.D. (2001). Assessing what really matters to student learning: Inside the National Survey of Student Engagement. Change, 33(3), 10-17. 